\title{
Laparoskopik low anterior rezeksiyon sonrası oluşan anastomoz darlığında balon dilatasyon uygulaması: İki olgu sunumu
}

\author{
Endoscopic balloon dilatation of colorectal anastomotic stricture after low anterior resection: \\ Two case reports
}

Sezgin YILMAZ, Ahmet BAL, Ziya Taner ÖZKEÇECİ, Rüçhan Bahadır CELEP, Mustafa ÖZSOY, Ogün ERŞEN, Nazan OKUR, Yüksel ARIKAN

\section{ÖZET}

Benign anastomoz darlıkları kolorektal cerrahi sonrası ortaya çıkabilen geç komplikasyonlardandır. Tedavide her ne kadar endoskopik girişimler önerilmekteyse de balon dilatasyonu düşünülmesi gereken ilk seçenektir. Laparoskopi yardımlı low anterior rezeksiyon ve stapler anastomoz yapılan iki hastamızdan birinde postoperatif 6 . ayında diğgerinde ise 9. ayında ileri derecede anastomoz striktürü tespit edildi. Hastalardan biri ishal-kabızlık atakları, rektal kanama gibi yakınmalarla başvururken diğer hasta tamamen asemptomatikti ve anastomoz darlığı kontrol kolonoskopisinde saptand1. Her iki hastaya da akalazya tedavisinde kullanılan "ower-the-wire" balonu ile iki seans endoskopik dilatasyon uyguland.

Anahtar kelimeler: Anastomoz darlığı, Balon dilatasyon, Low anterior rezeksiyon

\begin{abstract}
Benign anastomotic strictures develop in the late period after colorectal surgery. Although many endoscopic interventions are recommended in the treatment, the first option is balloon dilatation. We report two patients with colorectal tumors. We performed laparoscopy-assisted low anterior resection and stapler anastomosis. On the sixth and ninth postoperative months anastomotic strictures occurred. One of the patients was symptomatic with diarrheaconstipation episodes and rectal bleeding but the other patient was asymptomatic and anastomotic stricture was revealed in control colonoscopy. The patients underwent over-the-wire balloon dilatation which is used in the treatment of achalasia. Both patients had two sessions of endoscopic dilatation.
\end{abstract}

Keywords: Anastomotic stricture, Balloon dilatation, Low anterior resection

Sezgin Yılmaz (凶), Ahmet Bal, Ziya Taner Özkeçeci, Rüçhan Bahadır Celep, Mustafa Özsoy, Ogün Erşen, Yüksel Arıkan

Genel Cerrahi Anabilim Dalı, Tip Fakültesi, Afyon Kocatepe Üniversitesi, Afyonkarahisar, Türkiye

e-mail:syilmaz@aku.edu.tr

Nazan Okur,

Radyoloji Anabilim Dall, Tip Fakültesi, Afyon Kocatepe Üniversitesi, Afyonkarahisar, Türkiye

Gönderilme/Submitted: 03.10.2014

Kabul/Accepted: 21.11.2014

\section{Giriş}

Kolorektal cerrahi operasyonu postoperatif dönemde, anastomoz hattında ortaya çıan benign anastomoz striktürleri genellikle stapler kullanımı, anastomoz kaçağ1, bağırsakta veya sütür hattında iskemi veya radyoterapi gibi faktörlerin etkisi ile gelişen darlıklardır [1,2]. Kolonoskopun anastomozdan geçirilememesi veya klinik olarak hastada tıkanma semptomlarıla birlikte radyolojik bulguların varlığı anastomoz striktürü olarak tanımlanır [3,4]. Benign anastomoz striktürleri kolonik anastomozlardan sonra \%2-7 oranında görülürken [5,6], stapler yardımı ile yapılan kolorektal anastomozlarda bu oran \%5 ile \%22'ye kadar çıkar [7-9]. Anastomoz varlığı, hastaların pek çoğunda, endoskopik tedaviler ya da cerrahi tedaviye ihtiyaç gösteren ciddi klinik durumlara yol açmaktadır.

\section{Olgu Sunumu}

\section{Olgu}

Kliniğimizde 6 ay önce rektum 7. $\mathrm{cm}$ 'de tespit edilen tümör sebebiyle ameliyat olan 52 yaşında bayan hasta kabızlık-ishal atakları ve dışkılama sonrası rektal kanama şikayetleriyle polikliniğimize başvurdu. Anastomoz için stapler kullanılarak yapılan laparoskopi yardımlı aşağ1 anterior rezeksiyon sonrası, hasta evre 2 rektum adenokarsinomu olarak değerlendirildi ve herhangi bir adjuvant tedavi uygulanmadı. Takip programına alınarak üç hafta sonra stoması kapatılan hastada cerrahi girişimler sonrasında ve kontrollerde komplikasyon gelişmedi. Postoperatif 6. ayında ameliyattan önceki şikayetlerinin tekrarladığını belirten hasta son 1 aydır distansiyon ve non spesifik karın ağrısı yakınmalarının olduğunu beyan etti. Patlar tarzda gaita çıkışı olduktan sonra ishal şeklinde dışkıladığını ve rektal kanamasının olduğunu belirten hasta bu döngünün 2-3 günde bir tekrarladığını belirtti. Hastanın 
fizik muayenesinde özellik yoktu ve laboratuvar tetkikleri normal sinırlardaydı. Hastaya yapılan kolonoskopisinde 4. cm'de anastomoz görüldü, anastomozun ciddi oranda daraldığ 1 ve buradan $13 \mathrm{~mm}$ çaptaki standart endoskopun geçişine dahi izin vermediği görüldü (Şekil 1a). Skopi altında dar bölgenin distalinden verilen kontrast maddenin ince bir hat olarak anastomozu geçtikten sonra proksimal kolona ilerlediği görüldü (Şekil 2a). Kolonoskopi sırasında tümör nüksü açısından anastomozdan alınan biyopsi sonucu non spesifik iltihap olarak rapor edildi. Kontrol tomografisinde de herhangi bir nüks kitle olmamakla beraber anastomoz düzeyinde kum saati şeklinde konsantrik daralma saptandi (Şekil 3). Floroskopi altında yapılan incelemede anal kanala yerleştirilen $22 \mathrm{fr}$ foley sondadan verilen kontrast maddenin boyu $1 \mathrm{~cm}$ 'den kısa ancak genişliği oldukça dar bir striktür segmentini geçerek proksimale ilerlediği saptandı (Şekil 2a). Foley sonda anastomozun proksimaline geçirilmek istendiğinde ise başarılı olunamadı. Bunun üzerine hastaya endoskopik dilatasyon kararı alınarak akalazya dilatasyon balonu kullanılarak iki seans halinde dilatasyon yapıldı (Şekil 2b) ve darlığın işlem sonrası önemli oranda kaybolduğu saptandı (Şekil 1b). İki hafta sonra yapılan kontrol kolonoskopisinde anastomozun kolonoskopun geçişine rahatlıkla izin verecek ölçüde genişlediği saptandı ve hastanın şikayetlerinin kaybolduğu öğrenildi. (Şekil 1c).

\section{Olgu}

Altmış bir yaşında hipertansiyon dışında ek hastalığ bulunmayan erkek hastaya rektum $10 . \mathrm{cm}$ de malign kitle nedeniyle kliniğimizde laparoskopik aşağ1 anterior rezeksiyon yapıldı ve ileostomi açıldı. Yara yeri enfeksiyonu, apse, anastomoz kaçağı gibi komplikasyonlar gelişmeyen hasta postoperatif 8 . günde sorunsuz taburcu edildi. Spesimen patolojisi müsinöz adenokarsinom olarak gelen hastaya cerrahi sınırların negatif olması ve metastatik lenf nodu saptanmamasi sebebiyle radyoterapi tedavi verilmedi. Hastanın postoperatif dönemdeki poliklinik kontrolleri sorunsuz geçti. Herhangi bir gastrointestinal sistem yakınması mevcut olmayan hasta ameliyattan 9 ay sonra ileostomisi kapatılmak üzere çağırıldı. Hastaya ileostomisi kapatılmadan önce yapılan kontrol kolonoskopisinde 5. cm'de $13 \mathrm{~mm}$ çapındaki kolonoskopun geçişine izin vermeyecek ölçüde bir darlık tespit edildi. Darlık çevresinden alınan biyopsi sonucu kolon mukozası olarak gelen hastaya çekilen bilgisayarlı tomografide lokal nüks saptanmadi. Hastaya endoskopik dilatasyon yapılması planlandı ve birer gün arayla olmak üzere iki seans balon dilatasyon işlemi uygulandı. Bu süre zarfında dilatasyon sonucunda oluşan rektal erozyon ve ülserlere yönelik günde 3 kez sükralfatlı lavman uygulandı. 2 hafta sonra yapılan kolonoskopide anastomozdan zorlanmadan geçildi, pasajın açık olduğu ve rektal erozyonların kaybolduğu gözlendi. İleostomisi kapatılarak taburcu edilen hasta postoperatif 1 . ayında sağ ve sağlıklı olarak takip edilmektedir.

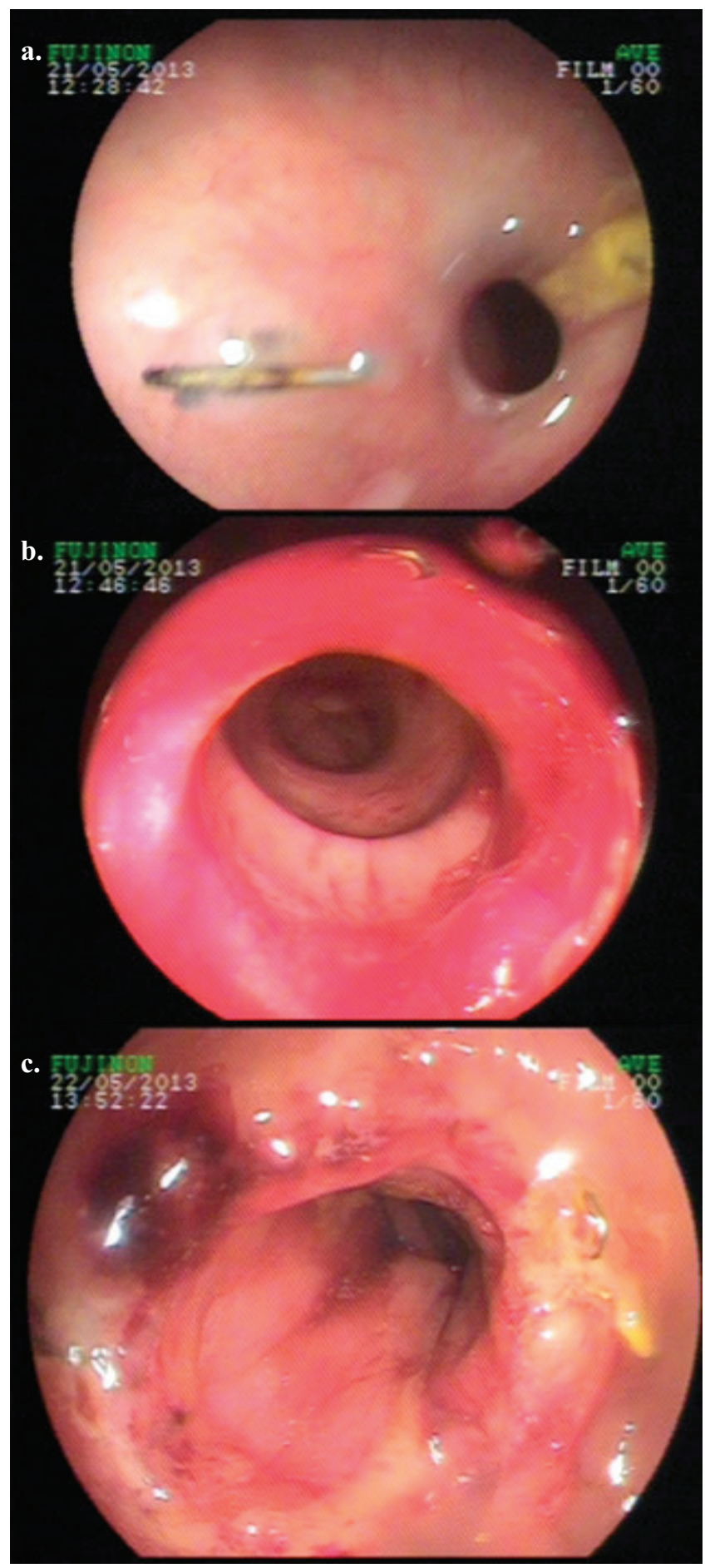

Şekil 1a,b,c. Anastomozdaki darlık, dilatasyondan hemen sonra ve iki hafta sonraki görünümü 


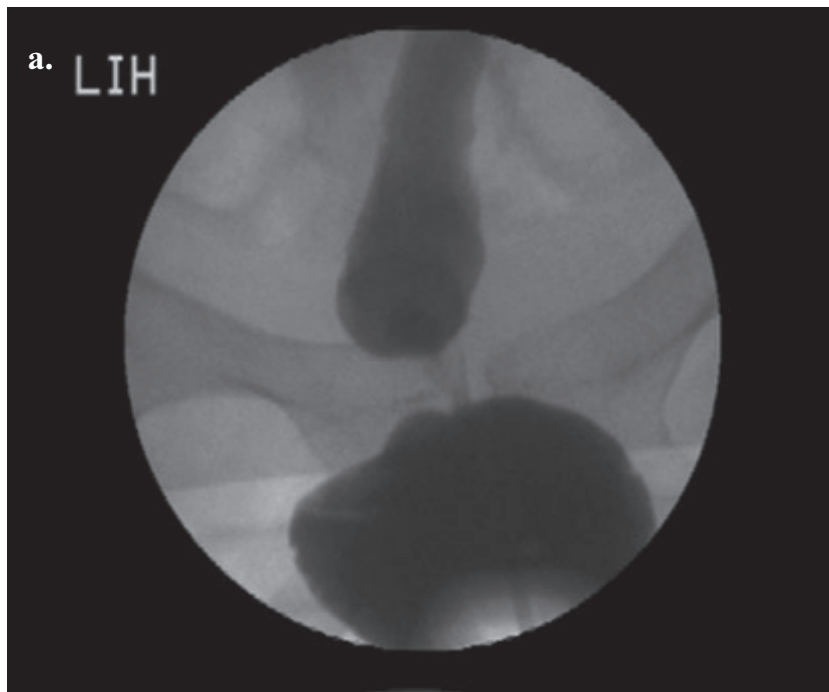

\section{Tartışma}

Kolorektal cerrahi sonrası görülen anastomoz darlıkları, kolonoskopun geçmesine izin vermeyecek kadar dar bir anastomoz lümeninin bulunması ve hastada bununla ilişkilendirilebilecek kabızlık, ishal, karın ağrısı, inkontinans veya kanama gibi yakınmaların olmasıyla tanınır [10]. Kolorektal cerrahisi sonrası görülen bu tür benign darlıklarda iskemi, radyoterapi, anastomoz hattından kanama dahil pek çok neden etiyolojik faktör olarak sorumlu tutulmuştur. Bizim de kliniğimizde laparoskopik aşağı anterior rezeksiyon ve anastomoz yapılan 14 olgudan ikisinde benign anastomoz darlığı gelişmiştir. Weinstock ve Luchtefeld bu darlıkların postoperatif 3 ay ila 10 yıl arasında görüldüğünü raporlamışlardır [11,6]. Hastalarımızdan ilki semptomatik iken, diğerinde anastomozdaki ileri derecedeki striktür herhangi bir gastrointestinal semptoma yol açmamış, yapılan kontrol kolonoskopisinde ortaya çıkmıştır. Anastomotik striktürlerin bir kısmı bağırsak tıkanıklı̆̆ yakınmalarını açıklamak amaçlı yapılan tetkikler esnasında saptanırken, bir kısmı ise kolonoskopide tesadüfen tanı alır. Delaunay ve ark.'nın çalışmasında hastaların \%22'si, Placer ve ark.'nın çalışmasında ise \%42'si asemptomatik olarak bildirilmiştir [12,3]. Anastomoz hattında oluşan lokal nüksler ile benign darlıkların ayrımında endoskopik ultrasonografi kullanılabilir ancak bizim kliniğimizde mevcut olmadığından bu tetkik yapılamamıştır.

Geçmişde tıbbi tedaviye yanıtsız anastomoz darlıklarının tümünde cerrahi tedavi uygulanırken günümüzde endoskopik

Şekil 2a,b. Anastomozdaki darlığın anal kanaldan kontrast madde verildikten sonra ve balon dilatasyon yapilırken floroskopik görünümü.

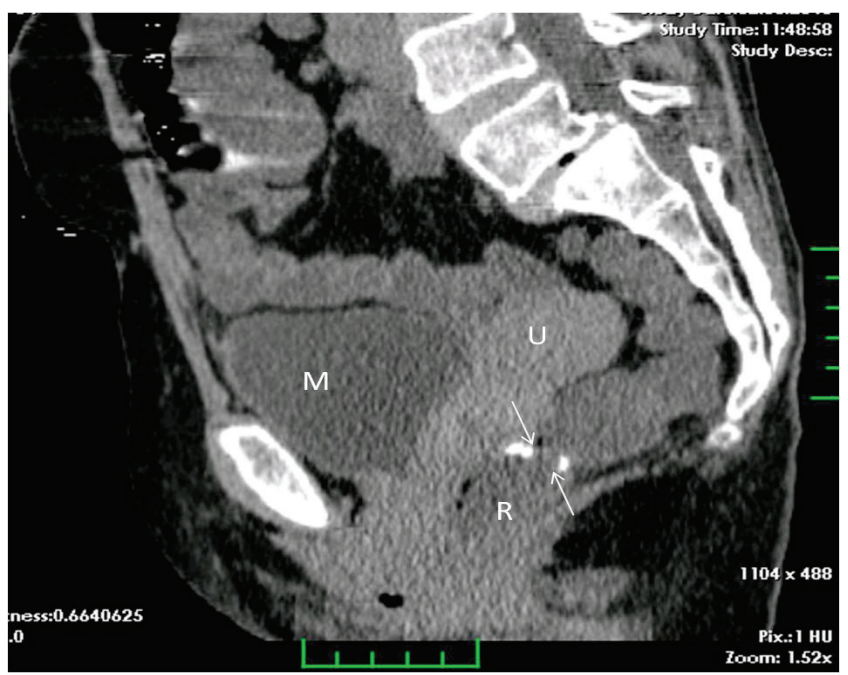

Şekil 3. Rektuma yönelik midsagittal reformasyon BT imaj1. Anastomoz düzeyinde, kum saati şeklinde, konsantrik luminal daralma izlenmekte (oklar). R: Rektum; U: Uterus; M: Mesane. yöntemlerdahakonservatifolduklariç̧inönplanaçıkmaktadır [13]. Bunlar arasinda Savary-Giliard polivinil bujiler [14] ya da balon ile dilatasyon [15], düzelmeyen vakalarda ise metalik stent uygulamaları sayılabilir [12]. Bazı vakalarda bunlarla kombine ya da ayrı olarak ND-YAG Lazer, ya da endoskopik retrograt kolanjiopankreatografi (ERCP) prekut iğnesi ile insizyon dilatasyonun başarısını arttırabilir ve böylelikle perforasyon riskini azaltabilir [16,17]. Bu hastalarda anastomoza endoskopik bakı altında iki-üç adet küçük radyal elektroinsizyon yapılarak 15-20 dakikalık balon dilatasyonu uygulanır [18]. Balon dilatasyonunda güç hem çevresel hem de radyal olarak etki eder. Böylelikle dilatasyon kuvveti tüm striktür boyunca etkisini gösterir ve rijid bujilerle yapılan dilatasyonlarda görülen yırtılma etkisi daha az görülür [10]. Ancak endoskopik tedavilerin uygulanması düşünülen vakalarda anastomozdan biopsiler alınıp tümör nüksünün ekarte edilmesi gerekir.

Anastomoz darlıklarında balon dilatasyonu minimal invaziv, başarı oranı yüksek ve uygulaması kolay bir 
yöntemdir. Hastaların \%30-40'ında tek bir seans yeterli olabilirken genel olarak ortalama 2 ile 4 seans dilatasyon gereklidir $[5,10,12]$. Dar alanın çapının $5 \mathrm{~mm}$ 'den az ve boyunun da $1 \mathrm{~cm}$ 'den fazla olduğu vakalarda endoskopik tedavilerin başarı şansı azdır ve girişim sonrası perforasyon oranları fazladır. Bu hastalarda cerrahi yaklaşım ön plana çıkar. Endoskopik tedavilerin yararlı olmadığı olgularda cerrahi girişim, mortalite ve morbiditesi yüksek olsa da uygulanması gereken tedavi şeklidir.

Anastomoz darlıklarında endoskopik balon dilatasyonu genellikle propofol anestezisi altında yapilır. Günümüzde endoskopik dilatasyonda iki adet balon tipi kullanılmaktadır. Through-the-scope (TTS) olarak adlandırılan balon kolonoskopun aksesuar kanalından girerek kolonoskopun görüşü ve floroskopi altında striktür alanına yerleştirilir. Over-the-wire (OTW) balon tipinde ise kılavuz tel anastomozdan geçirildikten sonra üzerinden balon ilerletilerek kolonoskopla direkt bak1 altında uygun pozisyon verilip şişirilir. Anastomozdaki balon yardımı ile gerçekleştirilen dilatasyon floroskopi altında gözlenebilir Hastalarımıza dilatasyon işlemi analjezi için petidin hidroklorür kullanılarak midazolam sedasyonu altında 14 fr klavuz tel anastomoz hattından geçirildikten sonra $35 \mathrm{~mm}$ çapta $10 \mathrm{~cm}$ uzunluğunda OTW akalazya balonu kullanılarak yapıldı. Her seansta dilatasyon balonu $2 \mathrm{kez}$ 3 'er dakika boyunca serum fizyolojik kullanılarak şişirildi ve ilk gün 15 per square inch (PSI) ikinci gün ise 20 PSI basınç uygulandi. (Şekil 4b). Giorgio ve ark. OTW ve TTS balonlarını karşılaştırma amaçlı yaptığı bir çalışmada, low anterior rezeksiyon sonrası oluşan benign anastomoz darlıklarında OTW balonu kullanıldığında daha az sayıda dilatasyon seansı uygulanarak başarıya ulaşıldığını ve bu balonla yapılan dilatasyon uygulamalarının daha güvenilir olduğunu tespit etmişlerdir [10]. Daha fazla dilatasyona ihtiyaç duyan olgularda işleme bağlı komplikasyon oranı da artar.

Olgu sunumumuzdaki iki hastanın da yapilan laparoskopik low anterior rezeksiyonu ile beraber açılan ileostomisi mevcuttu. Hastalarımızın biri ileostomi kapatıldıktan 5 ay sonra semptomatik anastomoz striktürü ile başvururken halen ileostomisi mevcut olan diğer hastada ise gastrointestinal tıkanıklık semptomları mevcut değildi. Hastadaki ileostominin distaldeki anastomoza ulaşan volüm yükünü azaltarak striktüre bağlı tıkanıklık semptomlarını perdelediği düşünüldü.

Sonuç olarak, kolorektal cerrahiden sonra sik görülen komplikasyonlardan olan anastomoz darlığının tedavisinde öncelikle düşünülmesi gereken endoskopik yaklaşımlar içerisinde balon dilatasyonu hızla uygulanabilen, başarı oranı yüksek ve komplikasyon oranı düşük minimal invaziv bir yöntem olarak ön plana çıkmaktadır.

\section{Kaynaklar}

1. Chung RS, Hitch DC, Armstrong DN. The role of tissue ischemia in the pathogenesis of anastomotic stricture. Surgery 1988;104:824-9.

2. Polglase AL, Hughes ES, McDermott FT, Pihl E, Burke FR. A comparison of end-to-end stapler and suture colorectal anastomosis in the dog. Surg Gynecol Obstet 1981;152:792-6.

3. Placer C, Urdapilleta G, Markinez I, et al. Benign anastomotic strictures after oncologic rectal cancer surgery. Results of treatment with hydrostatic dilation. Cir Esp 2010;87:239-43.

4. Kan H, Furukawa K, Suzuki H. An improvement in the quality of life after performing endoscopic balloon dilation for postoperative anastomotic stricture of the rectum. J Nippon Med Sch 2007;74:418-23.

5. Virgilio C, Cosentino S, Favara C, Russo V, Russo A. Endoscopic traitment of postoperative colonic strictures using an achalasia dilator: short-term and long-term results. Endoscopy 1995;27:219-22.

6. Weinstock LB, Schatz BA. Endoscopic alternatives in the management of the anastomosis following resection of colonic neoplasm. Gastrointest Endosc 1994;40:558-61

7. Tuson JR, Everett WG. A retrospective study of colostomies, leaks and strictures after colorectal anastomosis. Int $\mathrm{J}$ Colorectal Dis 1990;5:44-8.

8. Marchena GJ, Ruinz CE, Gomez GG, et al. Anastomotic stricture with the EEA-Stapler after colorectal anastomosis. Rev Esp Enferm Dig 1997;89:835-42.

9. Mukai M, Kishima K, Lizuka S. Endoscopic hook knife cutting before balloon dilatation of severe anastomotic stricture after rectal cancer resection. Endoscopy 2009;41:193-94. doi:10.1055/s-0029-1214776

10. Di Giorgio P, De Luca L, G, et al. Endoscopic dilation of benign colorectal anastomotic stricture after low anterior resection: A prospective comparison study of two balloon types. Gastrointest Endosc 2004;60:347-50.

11. Luchtefeld MA, Milsom JW, Senagore A, Surell JA, Mazier WP. Colorectal anastomotic stenosis. Results of a survey of the ASCRS membership. Dis Colon Rectum 1989;32:733-6. doi:10.1007/BF02562119

12. Delaunay K, Barthelemy C, Dumas O, Balique JG, Audigier JC. Endoskopic therapy of benign colonic postoperative strictures: report on 27 cases. Gastroenterol Clin Biol 2003;27:610-3.

13. Yaman İ, Derici H. Kolon benign anastomoz darlığında endoskopik balon dilatasyon. Kolon Rektum Hast Derg 2010;20:134-38.

14. Werre A, Mulder C, van Heteren C, Bilgen ES. Dilation of benign strictures following low anterior resection using Savary-Gilliard bougies. Endoscopy 2000;32:385-8. doi:10.1055/s-2000-8999

15. Solt J, Hertelendi A, Szilágyi K. Balloon catheter dilatation of lower gastrointestinal tract stenoses: long-term results. Orv Hetil 2002;143:1835-40.

16. Dieruf LM, Prakash C. Endoscopic incision of a postoperative 
colonic stricture. Gastrointest Endosc 2001;53:522-4. doi:10.1067/mge.2001.112369

17. Truong S, Willis S, Schumpelick V. Endoscopic therapy of benign anastomotic strictures of the colorectum by electroincision and balloon dilatation. Endoscopy 1997;29:845-
9. doi:10.1055/s-2007-1004319

18. Hoffmann JC, Heller F, Faiss S, et al. Through the endoscope balloon dilation of ileocolonic strictures: prognostic factors, complications, and effectiveness. Int $\mathrm{J}$ Colorectal Dis 2008;23:689-96. doi:10.1007/s00384-008-0461-9 